\title{
Carotid Stenting without Angioplasty
}

\author{
S. Men, S.P. Lownie, D.M. Pelz
}

\begin{abstract}
Background: Carotid angioplasty and stenting is gaining popularity as an alternative to carotid endarterectomy for the treatment of carotid bifurcation stenosis. The major concern with the procedure is the risk of embolic stroke which may be initiated by balloon angioplasty of friable atherosclerotic plaque. Elimination of angioplasty may result in a lower incidence of embolic complications. Method: We describe a case in which a self-expanding stent alone, without balloon angioplasty, was used to successfully dilate an atherosclerotic stenosis of the carotid bifurcation. Results: A moderate increase in vessel diameter, from $75 \%$ to $50 \%$, was immediately observed after stent placement alone. No embolic complications were observed and follow-up plain film and ultrasound examinations showed progressive stent enlargement with excellent anatomic and hemodynamic results. Conclusions: In this case of severe carotid stenosis, the use of a self-expanding stent alone, without balloon angioplasty, resulted in excellent anatomic and hemodynamic improvement.
\end{abstract}

RÉSUMÉ: Prothèse endovasculaire carotidienne sans angioplastie: à propos d'un cas. Introduction: L'angioplastie carotidienne et la mise en place d'une prothèse endovasculaire est une alternative de plus en plus populaire à l'endartérectomie carotidienne dans le traitement de sténoses de la bifurcation carotidienne. La préoccupation majeure associée à ce mode de traitement est le risque d'accident vasculaire cérébral embolique qui peut être déclenché par l'angioplastie par ballonnet de plaques athéroscléreuses friables. Méthode: Nous décrivons un cas chez qui seulement une prothèse endovasculaire auto-expansible, sans angioplastie, a été utilisée avec succès pour dilater une sténose athéroscléreuse de la bifurcation carotidienne. Résultats: Une augmentation modérée du diamètre du vaisseau, de $75 \%$ à 50\%, a été observée immédiatement après l'insertion de la prothèse endovasculaire. Aucune complication embolique n'a été observée et on a noté un déploiement progressif de la prothèse avec d'excellents résultats anatomiques et hémodynamiques sur les radiographies simples et à l'échographie au cours du suivi. Conclusions: Chez ce cas de sténose carotidienne sévère, un excellent résultat anatomique et hémodynamique a été obtenu par la mise en place d'une prothèse endovasculaire, sans angioplastie.

Can. J. Neurol. Sci. 2002; 29: 175-179

Although carotid angioplasty and stenting (CAS) is frequently used in many centers worldwide, there is still lack of proof of its safety, efficacy, and durability. ${ }^{1}$ Potential cerebral embolism during the procedure has been a major concern for CAS. Protective measures employing temporary vessel occlusion with various devices have been proposed and used effectively. ${ }^{2,3}$ Such measures, however, have not gained wide acceptance because of the concern that incorporation of an extra device to the regular angioplasty and stenting procedure would increase the number of manipulations, prolong the procedure time, and add to the procedural risk. An ideal protective method is not currently available. Whatever technique is used, minimizing the number of manipulations may be a simple means of reducing the risk of cerebral embolism. For example, if the self-expanding force of a stent provides a sufficient lumen without the aid of angioplasty, the angioplasty procedure could be totally omitted, which may reduce the risk. We present a case of symptomatic, severe carotid stenosis treated by deployment of a self-expanding metallic stent without balloon angioplasty.

\section{CASE REPORT}

A 76-year-old man presented with left hand weakness and a left facial droop. He had undergone bilateral carotid endarterectomies 18 years previously for atherosclerotic disease diagnosed after an episode of slurred speech. Magnetic resonance (MR) imaging showed multiple old small infarcts in both hemispheres, and areas of new diffusion abnormality in the right hemisphere, involving mainly the middle and anterior cerebral artery territories. MR angiography delineated a severe stenosis at the origin of right internal carotid artery. Carotid Doppler imaging (CDI) and subsequent digital subtraction angiography confirmed a right internal carotid artery stenosis which was $75 \%$

From the Department of Diagnostic Radiology, London Health Sciences Centre, University Campus, The University of Western Ontario, London, Ontario, Canada. Received OCtober 3, 2001. ACCEPTED in FinAl FORm JANUARy 9, 2002. Reprint requests to: David M. Pelz, Department of Diagnostic Radiology, London Health Sciences Centre, University Campus, 339 Windermere Road, London, Ontario N6A 5A6 


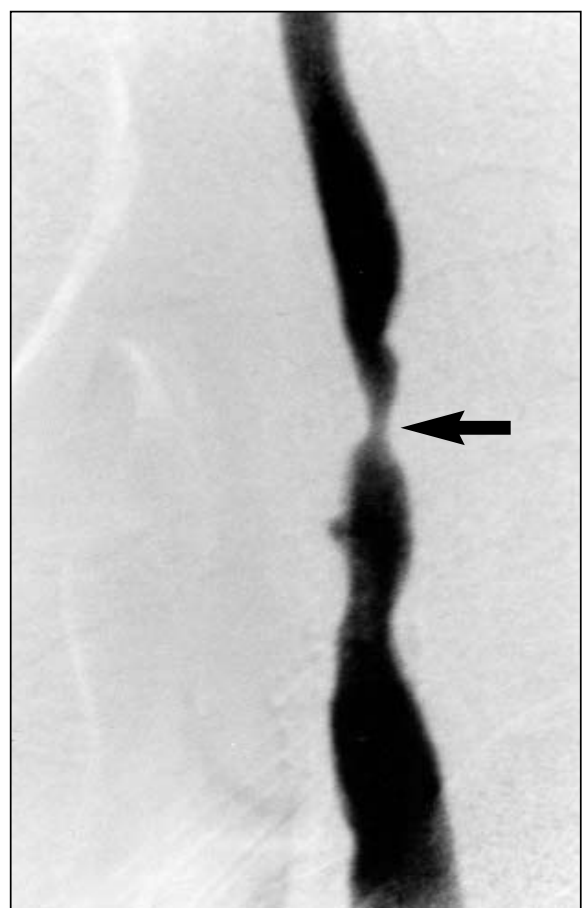

Figure 1A: Right common carotid digital subtraction angiography, lateral view, showing a severe $(75 \%)$ stenosis of the right internal carotid artery (arrow). The external carotid artery is occluded.

according to North American Symptomatic Carotid Endarterectomy Trial (NASCET) trial criteria (Figure 1A). ${ }^{4}$ The stenotic artery segment harbored calcified plaques and an ulcer. Because of previous surgery and accompanying medical problems which included diabetes mellitus, hypercholesterolemia, hypertension, and coronary heart disease, carotid endarterectomy (CEA) was not considered suitable, and the patient was referred for CAS.

Using a right transfemoral approach, a 7 French guiding sheath was placed in the proximal portion of the right common carotid artery. Under the guidance of a road map image, the stenotic segment was traversed by a 0.035 J-tip Glidewire (Terumo, Tokyo). The 7 French stent catheter was advanced over the wire and a Wallstent (Schneider/Pfizer Minneapolis, Mn), $8 \mathrm{~mm}$ diameter by $40 \mathrm{~mm}$ length, was deployed across the stricture. The Wallstent endoprosthesis is a self-expanding metallic stent which is composed of surgical-grade stainless steel alloy filaments. The stent spontaneously recovers its original diameter when released into a vascular lumen, owing to the spring characteristics of the individual filaments. The properties of the stent have been described in detail elsewhere. ${ }^{5}$

Immediately after deployment, the stent showed some expansion and decreased the stenosis degree from $75 \%$ to $50 \%$ (Figure 1B). To minimize the manipulations and assuming that further self-expansion of the stent would ensue, the procedure was terminated. The patient was kept heparinized during and after the procedure in a dose to maintain the activated clotting time between 250 and 300 seconds. Heparinization was discontinued on the day following the procedure and the patient was maintained on ticlopidine $250 \mathrm{mg}$ and aspirin $300 \mathrm{mg}$ daily.

Diffusion-weighted MR imaging obtained 24 hours after the procedure did not show any new diffusion abnormality. Neck

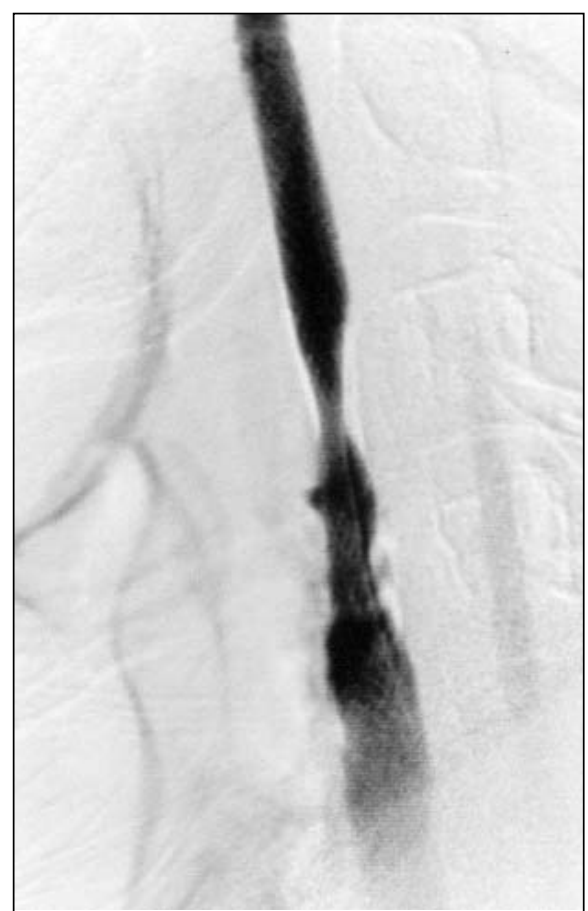

Figure 1B: Right common carotid digital subtraction angiography, lateral view following deployment of the Wallstent. The stenosis is now approximately 50\%.

radiograms and CDI obtained 48 hours later showed further expansion of the stent and improvement in intrastent flow (Figures 2,3). After a one-week observation, he was discharged. At one month, CDI and neck radiograms showed much further expansion of the stent and further improvement in carotid artery flow, which suggested only a mild residual stenosis (Figure 4). Internal carotid artery peak systolic velocity had decreased to $144 \mathrm{~cm} / \mathrm{sec}$ from $348 \mathrm{~cm} / \mathrm{sec}$ prior to the procedure, and the internal carotid artery/common carotid artery (ICA/CCA) velocity ratio had decreased to 3.7 from 11.6, thus confirming a hemodynamic as well as anatomic improvement.

\section{Discussion}

The major problem associated with carotid stenosis is atherothrombotic cerebral emboli rather than hemodynamic insufficiency. The goals of treatment in carotid stenosis should include eliminating the source of emboli in addition to reconstituting the normal flow in the artery. Carotid endarterectomy is an established method of treatment that achieves these goals. ${ }^{4}$ Carotid angioplasty, with or without stenting, also seems to achieve these goals, although the mechanisms involved are not thoroughly understood.

Angioplasty of the narrowed, atherosclerotic artery segment causes cracking and splitting of the atherosclerotic plaque, denuding of the overlying endothelium, dehiscence of the intimal layer from the underlying media, and stretching of the arterial wall. ${ }^{6}$ These events are thought to account for the immediate increase in arterial lumen after angioplasty. Transcranial Doppler performed during CAS procedures has shown that balloon 
A

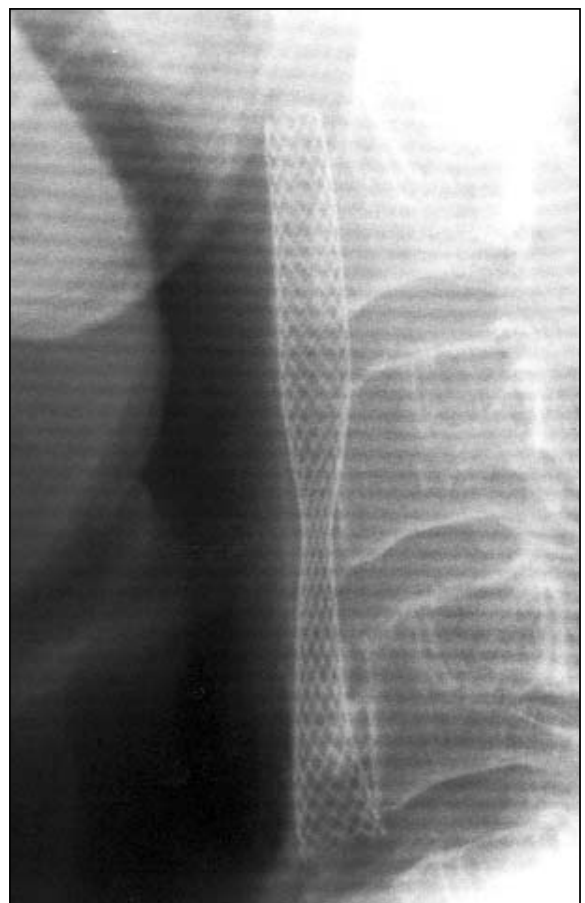

B

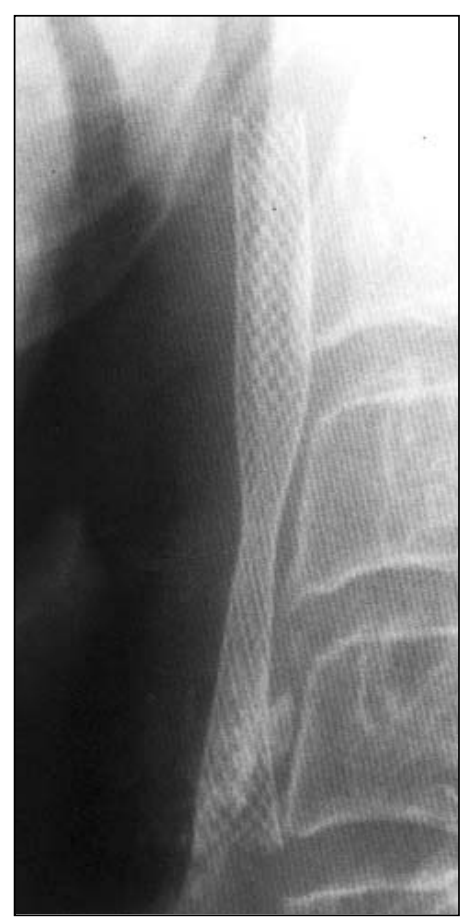

C

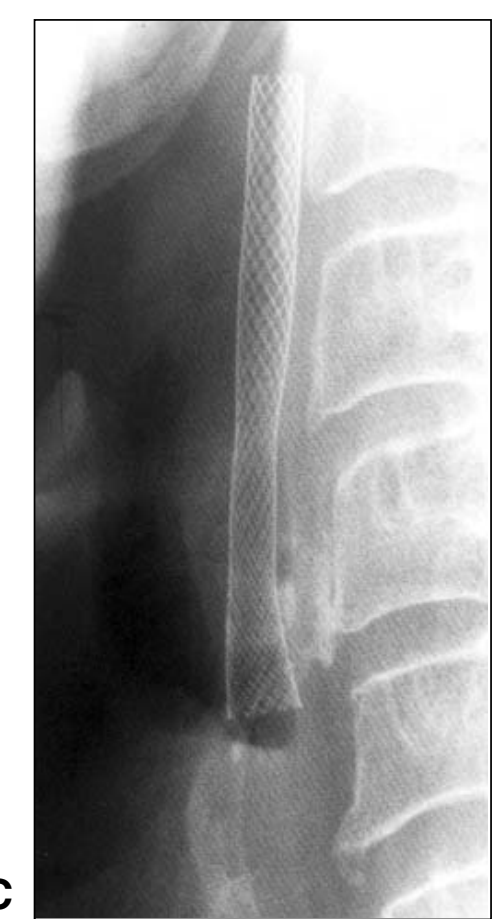

Figure $2 A, B, C:$ Lateral plain films of the neck immediately post-stent deployment $(A)$, three days $(B)$ and one month $(C)$ post-deployment, showing progressive enlargement of stent diameter.
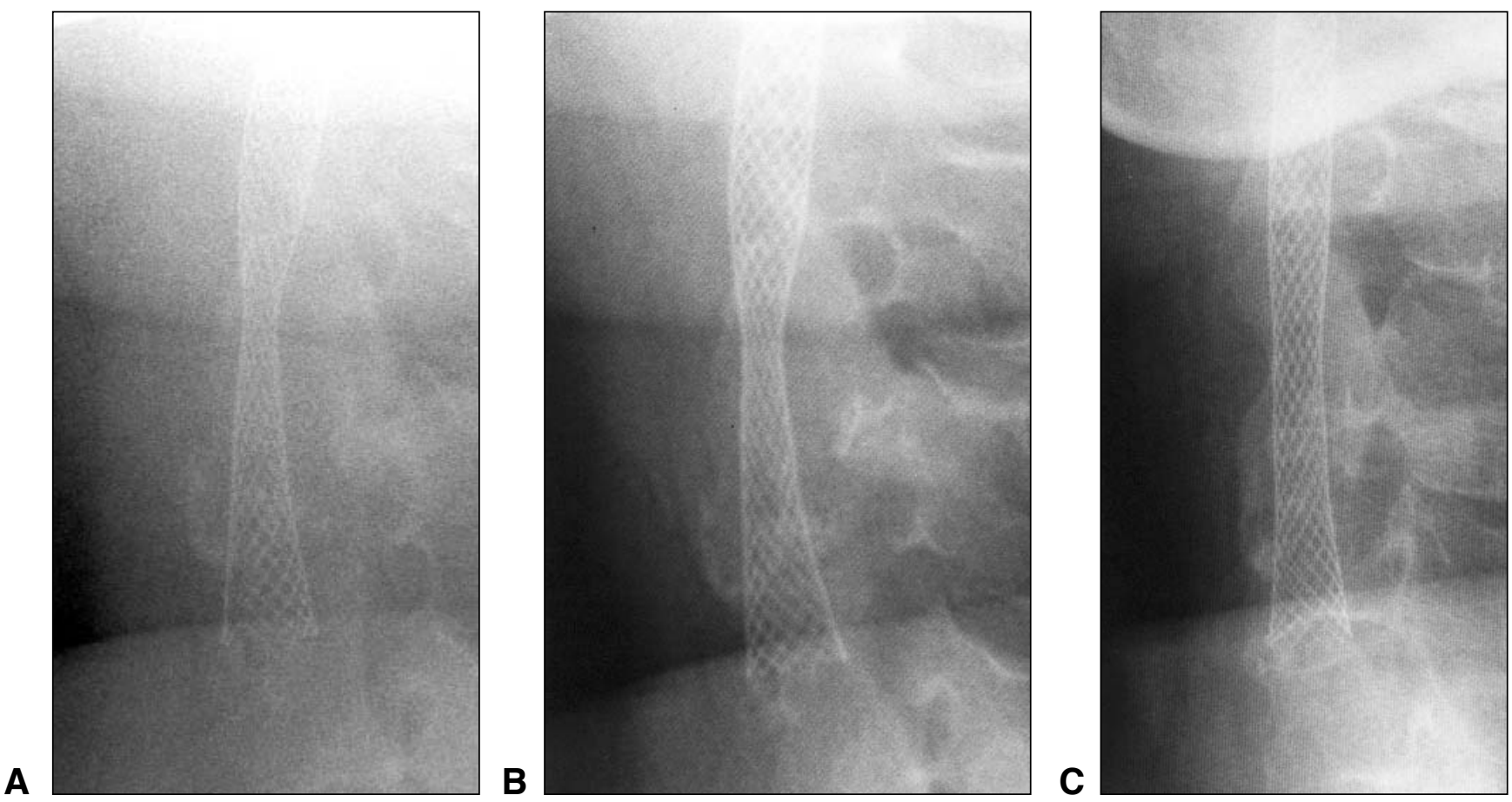

Figure 3A,B,C: AP plain films of the neck at the same time intervals of Figure 2, again showing progressive stent enlargement. 


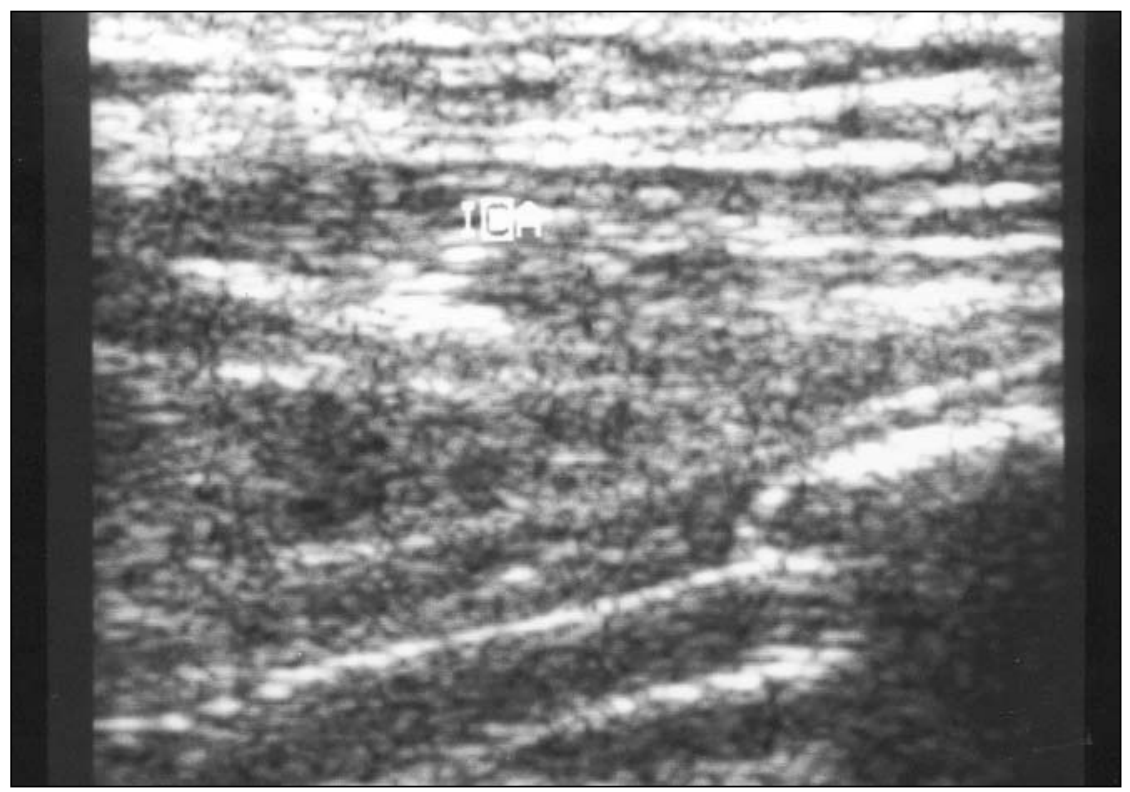

Figure 4: Carotid Doppler Imaging at one month post-stent deployment shows only a mild residual stenosis.

dilation of carotid bifurcation plaque results in a shower of micro-emboli to the intracranial circulation, up to eight times the rate observed during CEA. The vast majority of these emboli are asymptomatic. ${ }^{7}$ It was the desire to reduce this immediate risk of CAS that led to the elimination of balloon angioplasty in this case. Not only would there be less trauma to the arterial wall from the balloon, but shearing of atheroma from abrupt shortening of the Wallstent during post-stenting dilatation would also be eliminated.

This modification of CAS may also have long-term benefits. As the healing process continues after balloon angioplasty, the crevices and clefts in the plaque are covered by a neointima and smoothing of the contours is visible angiographically. The eventual lumen size is determined by the remodeling process: a perfect remodeling leads to expansion of the artery to accommodate neointimal formation, whereas unfavorable remodeling leads to severe luminal narrowing because of the failure to expand. ${ }^{8}$ Compared with balloon angioplasty, the vascular response to insertion of a stent is more extensive and takes a different form. In experimental animals, the neointimal lesions that arise following stent implantation have been as much as four times the size of those caused by balloon inflation alone within the same artery. In clinical studies as well, the late lumen loss after stenting outstrips that which follows balloon angioplasty alone, reflecting the accentuated intimal growth. ${ }^{9}$ These data, however, refer to the stents placed with angioplasty.

Insertion of self-expandable stents without balloon dilation in animal models has yielded encouraging results. ${ }^{8,10}$ Two types of Wallstent with different radial strengths were placed in femoropopliteal arteries of healthy dogs that underwent postmortem study four weeks and six months after stenting. ${ }^{10}$ The pathologic examination showed patency of the stents over the follow-up period with no evidence of stenosis. Neointimal overgrowth was complete and smooth in all cases. Medial atrophy was a constant finding after placement of both stent types. Neointimal thickness did not exceed $100 \mu \mathrm{m}$ after four weeks and six months and did not significantly differ between the two types of stents. In another study, ${ }^{8}$ three types of self-expanding Radius stents with different radial force were deployed in coronary arteries of pigs. At 28 days, arteries exposed to the low force showed loss in luminal area, whereas the moderate and high forces led to significant increases in luminal area. Thus the stent was responsible for gradually expanding the artery without causing damage to the vessel wall even in the high force group.

To the best of our knowledge, the application of selfexpanding stents in human arteries without balloon angioplasty has not been experienced before. However, Wallstents deployed in malignant biliary strictures without balloon inflation showed progressive self-expansion over the following days after stenting, and reached at least $85 \%$ of their nominal diameter. ${ }^{11}$ In our case also, the stent showed self-expansion over the following days and provided sufficient flow to the ipsilateral hemisphere.

It is realized that this technique may not be applicable in cases of severe, calcified carotid stenosis in which the stent may not cross the lesion without pre-dilatation by balloon angioplasty. The new generation of carotid stents, however, does possess smoother, lower diameter profiles, which facilitate less traumatic positioning. We believe that the avoidance of balloon angioplasty may minimize trauma to the arterial wall and thus decrease the risk of cerebral emboli. Stenting alone may be sufficient to restore adequate vessel diameter and promote a smooth neointimal remodeling process.

The gradual, relatively slow increase in vessel diameter may decrease the risk of reperfusion hemorrhage. We are currently accumulating further clinical data using stenting alone without angioplasty. 


\section{REFERENCES}

1. Connors III JJ, Seidenwurm D, Wojak JC, et al. Treatment of atherosclerotic disease at the cervical carotid bifurcation: current status and review of the literature. AJNR Am J Neuroradiol 2000;21:444-450.

2. Theron J, Courtheoux P, Alachkar F, et al. New triple coaxial catheter system for carotid angioplasty with cerebral protection. AJNR Am J Neuroradiol 1990;11:869-874.

3. Ferguson RDG, Lee LI, Connors JJ, Ferguson JG. Angioplasty in the extracranial and the intracranial vasculature. Semin Intervent Radiol 1994;2:64-82.

4. Ferguson GG, Eliasziw ME, Barr HWK, et al. The North American Symptomatic Carotid Endarterectomy Trial: surgical results in 1415 patients. Stroke 1999;30(9): 1751-1758.

5. Connors III JJ, Wojak JC, Qian Z. Tools of the trade. In: Connors III JJ, Wojak JC (Eds). Interventional Neuroradiology: Strategies and Practical Techniques. WB Saunders, Philadelphia;1999:1-37.

6. Zollikofer CL, Ferral H, Cragg AH, Castanada-Zuniga WR,
Amplatz K. Mechanism of transluminal angioplasty. In: Castaneda-Zuniga WR Ed. Interventional Radiology. London: Williams and Wilkins, 1997; 319-371.

7. Jordan WD, Voellinger DC, Doblar DD, et al. Microemboli detected by transcranial Doppler monitoring in patients during carotid angioplasty versus carotid endarterectomy. Cardiovasc Surg 1999; 7:33-38.

8. Schwartz RS. Pathophysiology of restenosis: interaction of thrombosis, hyperplasia, and/or remodeling. Am J Cardiol 1998;81(7A):14E-17E.

9. Edelman ER, Rogers C. Pathobiologic responses to stenting. Am J Cardiol 1998;81(7A):4E-6E.

10. Vorwerk D, Redha F, Neuerburg J, Clerc C, Gunther RW. Neointima formation following arterial placement of self-expanding stents of different radial force: experimental results. Cardiovasc Interv Radiol 1994;17:27-32.

11. Men S, Hekimoglu B, Kaderoglu H, et al. Palliation of malignant obstructive jaundice: use of self-expandable metal stents. Acta Radiol 1996;37:259-266. 